\title{
Trajetórias do patrimônio cultural e os sentidos dos seus usos em Paraty (RJ)
}

\section{Trajectories of cultural heritage and the meaning of its uses in Paraty (RJ)}

\author{
Maria Tereza Duarte Paes ${ }^{1}$ \\ paes.tereza@gmail.com
}

\section{Resumo}

A preservação dos sítios coloniais no Brasil, quer tenha sido pelo seu abandono ou pela institucionalização do tombamento, serviu de âncora para a refuncionalização turística e para a ascensão econômica de inúmeras cidades brasileiras nas últimas décadas, processo que deve atentar para as articulações necessárias entre patrimônio cultural, valorização turística e planejamento territorial. Nesse sentido, partimos do pressuposto de que o processo de patrimonialização, ou a revalorização de sítios históricos já anteriormente tombados, tem caminhado pari passu ao processo de renovação urbana e de turistificação destas áreas, tema que será abordado aqui a partir do argumento empírico de Paraty, no Rio de Janeiro.

Palavras-chave: Refuncionalização turística; Sítios coloniais; Paraty, Rio de Janeiro.

\begin{abstract}
The preservation of the colonial sites in Brazil, whether through its abandonment or by the institutionalization of the official historical heritage, served as anchor for the touristic refunctionalization and economic rise of numerous brazilian cities in recent decades, a process that should pay attention to the necessary links between cultural heritage, tourism development and territorial planning. In this sense, we assume that the patrimonial process, or the upgrading of historical sites previously defined as official historical heritage, has walked pari passu with the process of urban renewal and touristification of these areas, an issue that will be discussed here from the empirical argument of Paraty, in Rio de Janeiro.
\end{abstract}

Keywords: Touristic refunctionalization; Colonial sites; Paraty, Rio de Janeiro.

1 Geógrafa, doutora em Ciências Sociais pela Universidade Estadual de Campinas (Unicamp) e professora do Departamento de Geografia do Instituto de Geociências na mesma universidade. Bolsista Produtividade CNPq. 


\title{
Introdução
}

O processo de refuncionalização turística (LUCHIARI, 2005; PAES, 2012) de sítios históricos, que chegou ao Brasil de modo mais contundente nos anos 1990, coloriu os antigos casarios coloniais, iluminou as edificações, expulsou a população local de moradores de baixo poder aquisitivo e levou para ali um novo modo de vida associado ao consumo cultural: festas, espetáculos, restaurantes, ateliês, bares, comércio turístico e turistas. $\mathrm{Na}$ maioria dos casos, como o conhecido exemplo do Pelourinho, ou do centro histórico de Salvador, Bahia (SANT’ANNA, 2003), estes antigos centros não conseguiram preservar a sua antiga população de moradores, o que acabou prejudicando a própria dinâmica turística, devido ao abandono destas áreas fora das temporadas ou no período noturno. Seja por meio de políticas públicas, de interesses imobiliários, ou de grupos sociais organizados, o fato é que estes antigos sítios ou centros históricos ${ }^{2}$ foram capitalizados e reincorporados ao tecido urbano e às políticas de promoção de imagem do planejamento territorial, tanto que, especialmente a partir dos anos 2000, estes se transformaram em objeto de políticas públicas urbanas e culturais, tais como o Programa de Reabilitaşão Urbana, com o foco em áreas centrais, criado juntamente ao Ministério das Cidades em 2003 (MINISTÉRIO DAS CIDADES, 2004; 2005); o Programa Monumenta, de 2000 e, atualmente, o Plano de Aceleração do Crescimento - Cidades Históricas (PAC-CH), vinculados ao Ministério das Cidades e ao Ministério da Cultura ou, especificamente, ao Instituto do Patrimônio Histórico, Artístico Nacional (Iphan) e às contrapartidas nas escalas municipais e estaduais do poder público. Nesse sentido, partimos do pressuposto de que o processo de patrimonialização, ou a revalorização de sítios históricos já anteriormente tombados, tem caminhado pari passu ao processo de renovação urbana e de turistificação destas áreas.

Esta valorização atual do patrimônio cultural arquitetônico no Brasil apoiou-se na herança de um processo de institucionalização que, em sua origem, nos anos 1930-1940, respondeu à produção de ideias, ideologias e teorias saídas das políticas públicas para representar os símbolos de um projeto nacionalista, constituído em política de estado por meio do SPHAN (atual Iphan), no governo de Getúlio Vargas, para a concertação de "valores civilizatórios, estéticos e morais, ao construírem um patrimônio nacional”. Segundo Chuva (2009, p. 31), no período de 1937 a 1946 o SPHAN "protegeu legalmente mais de 40\% de todo o patrimônio tombado até o começo do século XXI", fato que tomou como símbolo autenticamente nacional a arquitetura barroca colonial.

Embora o processo de patrimonialização contemporânea possa justificar-se pela necessidade de preservação da história social, sobretudo neste tempo de crise da matriz modernista, esta ilusão não se sustenta neste período de incorporação da cultura à nova vitalidade do capitalismo semiótico (PEET, 1997). A conveniência da cultura (YÚDICE, 2013) traduz-se com a reincorporação destes bens culturais à dinâmica das cidades, adaptados formal e simbolicamente ao novo contexto e aos novos atores sociais.

Ainda que nosso foco seja o valor do passado na vitalidade do presente, interessa-nos recuperar na história as formas e os sentidos que sustentaram as iniciativas da preservação, e situar a valorização turística e as intervenções de renovação urbana a elas associadas.

Paraty, no sul fluminense, tem uma história particular neste processo, e é ela que conduzirá os argumentos apresentados neste artigo.

\section{Paraty (RJ) - A joia esquecida nas trilhas e caminhos da história patrimonial}

\begin{abstract}
A história do Brasil é jovem de cinco séculos - ao menos se nos fiarmos na narrativa oficial, que inicia sua contagem a partir do desembarque dos portugueses na América -, e é inquieta. Uma vezprovocada, fala de tudo e adora embarcar numa polêmica: passa a limpo conceitos e mitos, questiona muitas das perguntas que nos habituamos a fažer sobre o país, mostra tendências e recorrências que bem merecem nova interpretação. Também faz um jogo com o tempo: embaralha, ordena e reordena o fio da meada; põe um olho no passado, mas mantém o outro aberto no presente e até no futuro. (SCHWARCZ, L.M. e STARLING, H.M., 2015, p. 499).
\end{abstract}

2 A conceituação de centros históricos ainda é pouco precisa para os órgãos da preservação patrimonial no Brasil. Não há um rigor conceitual que fixe os conceitos na continuidade do tempo. Assim, monumentos, conjuntos arquitetônicos, urbanísticos, sítios históricos, paisagísticos vão se sucedendo de acordo com o momento histórico e político e o contexto intelectual e imagético a influenciar as deliberações em seus Conselhos. Diante desse quadro, optamos por utilizar simplesmente a denominação sítios históricos para cidades menores e centros históricos para as cidades grandes que tiveram nas áreas centrais o núcleo formador de sua origem (PAES, 2012, p. 320). 
Entre o mar, a Serra da Bocaina e o maciço do Cairuçu, no alto do Morro Forte, seguindo os critérios da colonização portuguesa que buscava a existência de água potável, terrenos férteis, segurança e comunicação, colonos de São Vicente deram origem ao povoado de Paraty, pertencente à freguesia de Angra dos Reis, localizada na região da Baía da Ilha Grande, ao sul do estado do Rio de Janeiro. Em 1646 é erguida a Matriz da Nossa Senhora dos Remédios, local onde viria a ser o seu sítio histórico, entre os rios Paratiguaçu (hoje Perequê-Açú) e Patitiba. Em 1660 o povoado ganha autonomia política e separa-se de Angra, tornando-se a Villa de Nossa Senhora dos Remédios de Paratii ${ }^{3}$ em 1667.

Entre trilhas, ouro, viajantes, porto, o povoado que acompanhava a orla do mar adaptou-se às condições topográficas do sítio para atender às funções militares, administrativas e religiosas, seguindo o modelo português de traçado ordenado por edifícios públicos: igrejas, Casa de Câmara e Cadeia.

Com um conjunto arquitetônico de tipologia típica das cidades mineiras, encaixado em uma planície litorânea, configurou-se entre as cidades melhor assistidas pela Coroa portuguesa, devido ao seu papel de porto do ouro, embora o ouro não tenha figurado na paisagem de Paraty como o fez nas cidades mineiras (PLANO DE GESTÃO, 2008, p. 10). Em 1717 Paraty era um povoado pobre, com menos de 50 casas térreas em taipa e cobertas de sapê. "Com o crescimento populacional, formaram-se as irmandades, que expressam a diferenciação social na vila. A Igreja de Santa Rita foi edificada, em 1722 pelos pardos libertos [...] e em 1725, foi edificada pelos escravos a Igreja de Nossa Senhora do Rosário" (CURY, 2007, p. 179).

Foram as trilhas e os caminhos que sustentaram a funcionalidade de sua localização no escoamento de produtos essenciais à vida dos povoados. A mata densa e a proximidade com a serra íngreme não deixavam o povoado prescindir destes, sobretudo da trilha dos índios Guaianás, “já aberta e descoberta por Salvador Correia de Sá e Benevides, em 1660” (RIBAS, 2003, p. 13), que possibilitou o desenvolvimento de Paraty como porto de escoamento do ouro das Minas Gerais para o Rio de Janeiro e a ligação deste com São Paulo.

O desvio do leito do rio Perequê-Açu da barra do Jabaquara para o Pontal, em 1728, deixou abandonada a antiga Vila Velha do Morro do Forte, local de formação da cidade.

No período do ouro surge em Paraty a elite comerciante responsável pela construção dos sobrados de funcionalidade mista: o comércio na parte térrea e a residência na parte de cima. As técnicas construtivas das edificações seguiam as referências do período colonial: casas em taipa de pilão, erguidas a partir do socar do barro, areia, pedras e cal em uma forma; o pau-a-pique, técnica que preenche com barro uma grade feita em bambu e que poderia ser utilizado em paredes não estruturais; e as construções mais suntuosas, como igrejas, erguidas pela arte barroca do século XVII, em alvenaria de pedra, argamassa de barro, areia e cal.

O Caminho Velho do ouro favoreceria Paraty durante muito tempo ainda, sustentando o escoamento de pedras preciosas, do ouro e do café.

Com a transformação do Rio de Janeiro em capital colonial, no final do século XVIII, Paraty torna-se um grande produtor de cana-de-açúcar e cachaça, fato que imprime nova dinâmica à Vila. São de 1799 as primeiras Posturas Municipais a normatizar os gabaritos das construções, as medidas de portas e janelas e a exigir o muramento dos terrenos vazios. Paraty já possuía mais de 400 casas, entre 40 sobrados, e constrói o Forte Defensor Perpétuo (1793), no alto do morro da vila velha.

Tal dinamismo é acentuado no século XIX. No lugar do ouro, é o café do Vale do Paraíba, transportado em tropas de muares, que estimularia a construção da cidade, assim denominada em 1844. A Câmara Municipal da Vila de N.S. dos Remédios de Paraty promulgou o Registro de Posturas, em 1831, que determina: o alinhamento das fachadas; a proibição de casas de madeira e tetos de palha, para evitar incêndios; a demolição de ruínas e o calçamento do restante das ruas. É desse período a maior parte das edificações do sítio histórico, e o início das ações em prol dos ideais de embelezamento e salubridade que viriam a influenciar as cidades brasileiras:

As ruas ganharam uma leve inclinação em direção ao mar, uma calha central para o escoamento das águas e começaram a ser calçadas com pedras redondas conhecidas como pé-de-moleque [...]. A população chegou a 10 mil habitantes (PLANO DE GESTÃO, 2008, p. 13).

3 De acordo com Ribas (2003, p. 17), "Paraty herdou seu nome do peixe da família da tainha [...]. Hans Staden menciona o mesmo peixe como chamando-se 'pirati' [...]. Pode ser também que o nome venha da palavra 'parahy', que significa pequena enseada”. Os índios da região a denominavam Paratii; com a chegada dos jesuítas, devido à fonética do duplo 'ii', a cidade passou a ser chamada de Paraty. 
Ao sabor do café, sua economia e população cresciam. Em 1833, Paraty possuía 9.653 habitantes, incluindo 3.525 negros escravizados e 29 estrangeiros, e multiplicam-se os engenhos e as fábricas de destilação de aguardente. Suas casas geminadas, com pouca ventilação, e um sítio geográfico muito vulnerável às inundações, chamaram a necessidade dos melhoramentos urbanos. É deste período a construção do Mercado, do Chafariz, do cemitério, da ponte de desembarque, das praças, o calçamento de ruas e do Caminho Velho da Serra. No entorno da Praça Municipal, onde até 1858 era proibida a construção de casas térreas, o conjunto arquitetônico erguia-se com os sobrados dos ricos fazendeiros.

As melhorias urbanas, especialmente nas regiões portuárias, eram consonantes às concepções sanitaristas do período e à inserção do Brasil no capitalismo mundial. Para Costa (1987, p. 15), "Desde o momento em que se instaura a hegemonia das classes ligadas à produção capitalista do café, foram buscados padrões de atuação sanitária diferentes dos que predominam no período escravista”.

Mas o fim do tráfego de negros escravizados e a abertura do caminho ferroviário para o transporte do café entre Rio e São Paulo, no Vale do Paraíba, levaram Paraty a perder população no final do século XIX. O abandono do Caminho Velho refletiu-se no isolamento de Paraty. Sem a dinâmica do comércio, a energia de trabalho dos negros libertos e sem o seu papel de rede de ligação de fluxos econômicos variados, Paraty chega doente ao final do século XIX. A malária, a cólera, a febre amarela, a falta de esgoto, a emigração, a desvalorização dos imóveis, a ausência de profissionais e serviços, a vegetação crescendo sobre as plantações e engenhos, desenharam um cenário de abandono. A própria morfologia urbana, ao perder a sua função, decai. Numa visão tenebrosa, Gurgel e Amaral (1973, p. 49-50) escrevem:

\begin{abstract}
A malária instalara-se definitivamente no município, e afugentava os que ainda porfiavam na lida do campo, plantando escassamente ainda. Quilômetros e quilômetros de estradas jaziam sob um lençol de água pútrida, onde enxameavam mosquitos. O êxodo dos paratienses continuava [...]. As casas começaram a ruir, os sobradões coloniais abandonados não encontravam quem os quisesse comprar, nem mesmo por suas obras de talha, mármores e ladrilhos franceses. O comércio vegetava pobremente, e até a sua afamada cachaça, a Azulzinha, desaparecia do mercado. Onde antes eram engenhos e plantações de cana, existiam agora apenas bananais. As grandes fazendas de outrora se transformaram em pastos de reses magras e quartéis da malária.
\end{abstract}

Até o final do século XIX, não havia água encanada em Paraty, e como o seu assentamento estava próximo do mar, não era possível a construção de poços ou cisternas. As construções de dois chafarizes, no Largo Santa Rita e na Praça do Chafariz, tiveram o papel de atenuar tal carência.

O café do Vale do Paraíba desnudou morros e abriu novos caminhos entre as vilas do Vale e do litoral, deixando a bela Paraty perder a sua primazia no escoamento de produtos entre Rio e São Paulo. E assim, isolada, mas com um passado vivo em suas heranças formais e simbólicas, a joia da Coroa brasileira fica esquecida por meio século. Este isolamento de Paraty, assim como de inúmeros bairros caiçaras do litoral norte paulista no mesmo período, permitiu a preservação das edificações do sítio histórico, assim como a reprodução de uma cultura particular, material e imaterial

A maioria das edificações de Paraty não possui valor excepcional isoladamente, contudo, é pelo seu conjunto arquitetônico colonial e paisagístico, incluindo a Mata Atlântica em seu entorno, que este todo morfologicamente coerente irá ganhar valor. Assim, em 1945 a cidade é nomeada Monumento Estadual do Rio de Janeiro, sob a supervisão da Diretoria do Patrimônio Histórico e Artístico Nacional (DPHAN). Segundo Rodrigo Melo Franco de Andrade, diretor geral do DPHAN:

Ao contrário de outras cidades coloniais, a arquitetura de Paratí [sic] mostra-se mais interessante, tem mais caráter, originalidade e definição, não apenas nas edificações eruditas, como nas de sabor popular. A beleza arquitetônica de Parati deve-se principalmente ao equilíbrio de proporção e pureza dos partidos arquitetônicos. (IPHAN, 1958, Coleção de Monografias, Conselho Nacional de Estatística, n. 374).

Em 1947, a Prefeitura Municipal de Paraty aprova o Decreto-Lei no 51, de 27 de maio de 1947 do 
Código de Obras, o zoneamento e a zona urbana que delimita o perímetro do centro histórico, cabendo destacar que a análise do Código de Obras foi assinada por Carlos Drummond de Andrade, com pareceres positivos de Lucio Costa e Rodrigo Melo Franco de Andrade. Paraty é, então, redescoberta, e passa a ser reinventada.

\section{Paraty (RJ) - de Monumento Nacional à Patrimônio da Humanidade}

Em 1957, Carlos Drummond de Andrade, chefe de Seção de História da Divisão de Estudos e Tombamentos (DET) do Iphan (1958), inscreve a solicitação de tombamento do Conjunto Arquitetônico e Paisagístico da cidade junto ao órgão federal de preservação. Rodrigo Melo Franco de Andrade, à frente do DPHAN, aprova a inserção do conjunto no Livro do Tombo Arqueológico, Etnográfico e Paisagístico e no Livro do Tombo das Belas Artes, em 1958.

O conjunto arquitetônico e paisagístico de Paraty passa a ser objeto de estudo e preocupação daqueles que lhe reconheciam pelo seu valor histórico conservado. Inicialmente, temeu-se pela desfiguração de seu conjunto urbano, composto especialmente pela arquitetura colonial do século XVIII e início do século XIX, devido às intervenções de uso e renovação sempre recorrentes. Aos poucos, a preocupação ampliou-se para o seu entorno natural, ou seja, as encostas da Serra da Bocaina (Imagem 1).

Imagem 1 - Vista do conjunto arquitetônico e paisagístico de Paraty.

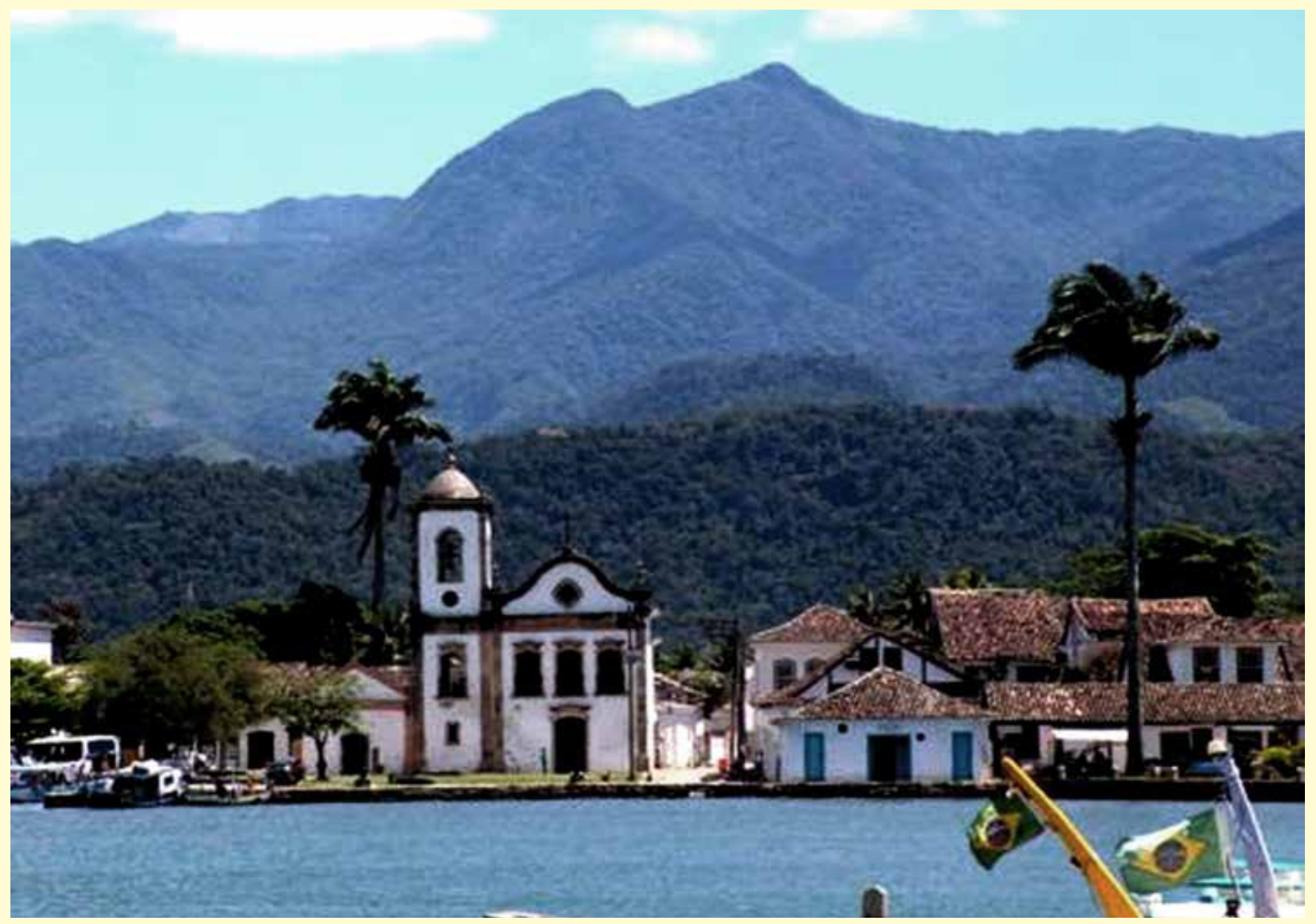

Fonte: Temporada (2015).

O Conde belga Frederic de Limburg Stirum, arquiteto que transitava entre os nomes influentes do DPHAN e da Unesco, amante de Paraty, chegou a redigir um Relatório para a Unesco, que deveria fundamentar o seu primeiro Plano Diretor. Em 1965, escrevia: 
Dossiê

[...] se as casas coloniais se mantém presentes, belas e altivas, construções recentes, de mau gosto, principiam a envolver a cidade, enquanto as florestas são devastadas. Pouco a pouco a paisagem se enfeia. Por outro lado, o desflorestamento provoca as erosões, empobrece o solo, estanca os mananciais e arruína a região. O Plano delineia um programa global de extensão da cidade, preservando as belezas e os recursos de Paraty. O partido nele adotado é simples: isolamento do bairro histórico num escrínio de vegetação e, por traz dessa moldura, criação da cidade nova onde a arquitetura moderna mais ousada possa desenvolver-se. Por tal forma, a anarquia e a desordem urbanas serão banidas para sempre (IPHAN, 1958, fl. 29).

Nas lidas da patrimonialização ainda era cedo para conceber um tombamento com tal magnitude, o município ${ }^{4}$, e também para somar-se às vozes dos ambientalistas que só chegariam à região no final dos anos 1970. Mas, é bem verdade, a proteção da cidade de Paraty estava atrasada em relação às cidades mineiras, tombadas entre os anos 1930-1940, e Paraty era filha da mesma história, representava as mesmas ideologias, possuía um belo acervo e estava ameaçada pela urbanização, pela proliferação de chácaras e pelo turismo.

A partir de 1964, o governo federal passa a intervir mais diretamente na educação, na cultura e, em 1966, cria a Empresa Brasileira de Turismo (Embratur). Este namoro entre os dois setores, cultura e turismo, não significava uma atitude isolada do Brasil, e sim a sua inserção em um processo mais amplo que o levaria a assinar a Carta de Quito, em 1967, resultado da Convenção da Organização dos Estados Americanos (OEA) que recomendava fortemente a associação entre patrimônio histórico e turismo para corrigir o estado de abandono dos bens culturais em países à margem do desenvolvimento econômico e social na América. Segundo as Normas de Quito (O.E.A., 1967, Art.VIII, cap.2):

Si los bienes del patrimonio cultural juegan tan importante papel en la promoción del turismo, es lógico que las inversiones que se requieren para su debida restauración y habilitación dentro de su marco técnico especializado, deben hacerse simultáneamente a las que reclama el equipamiento turístico y, más propiamente, integrar ambas un solo plan económico de desarrollo regional. ${ }^{5}$

Todos estes fatos associados somam argumentos para que, em 1966, o Decreto no 58.077 (BRASIL, 1966), nomeie Paraty Monumento Nacional, status já conferido às cidades de Ouro Preto, Mariana e Alcântara para viabilizar, no planejamento, a proteção do patrimônio em risco por degradação ambiental e urbana. Em virtude deste decreto, o DPHAN obteve assistência técnica da Unesco e contratou estudos apoiados pela Financiadora de Estudos de Projetos S.A. (Finep) para elaboração do plano urbanístico de Paraty, adequado à preservação do seu patrimônio arquitetônico e natural, tendo selecionado, após concorrência com outros seis projetos, a empresa Consórcio Nacional de Planejamento Integrado (IPHAN, 1958, Processo de Tombamento no 2.489/1969, fls. 35h-36h).

Ainda na década de 1970, ocorre a criação de uma série de áreas naturais protegidas para "garantir a conservação da paisagem natural, da Mata Atlântica e dos seus principais atributos, como a biodiversidade, a beleza cênica e as manifestações culturais tradicionais" (PLANO DE GESTÃO, 2008, p. 182). Segundo o Plano Diretor de Desenvolvimento

4 A Carta de Veneza (1964) amplia algumas concepções da Carta de Atenas (1933), criando novas metodologias para a necessidade de reconstrução após a $2^{\mathrm{a}}$ Guerra Mundial. Entre elas, amplia espacialmente a proteção do monumento histórico isolado para todo o seu conjunto significativo, ou seja, “o sítio urbano ou rural que dá testemunho de uma civilização particular” (Carta de Veneza, Artigo $1^{\circ}$ ) e, em relação às tipologias, inclui também as obras modestas de grande significação cultural. Além disso, introduz a concepção de "restauro crítico" em relação ao "restauro filológico" apresentado na Carta de Atenas (KUHL, 2010).

5 "Se os bens do património cultural desempenham um papel tão importante na promoção do turismo, é lógico que os investimentos necessários para a sua devida restauração e adequação, dentro do seu quadro técnico especializado, deverá ser feita, simultaneamente, para a demanda do equipamento turístico e, mais adequadamente, integrar ambas em um único plano de desenvolvimento económico regional" (tradução nossa).

6 "A Unesco proporcionou a vinda de um Técnico, Sr. Michel Parent, Inspetor Principal dos Monumentos Franceses, que em 1966 examinou a situação de Paraty" (IPHAN, 1958, Processo no 275.495/1970, Parecer n 24/1970). Para análise mais detalhada sobre a contribuição de Michel Parent, ver especialmente Leal (2008). 
Turístico de Paraty (2003), 80\% do território de Paraty é composto por Unidades de Conservação ${ }^{7}$, medida importante para a proteção de seu patrimônio natural, mas insuficiente para a proteção da cultura das populações de pescadores-lavradores caiçaras que, direta ou indiretamente, foram expulsas de seus territórios, seja pela proibição de suas práticas, particularmente a caça e a coleta, ou pela valorização de suas terras com a entrada do turismo.

Mas o final do século XIX até meados do século XX, período de um relativo isolamento da cultura caiçara, é pouco retratado nos documentos patrimoniais; só resta a ideia de um isolamento que viria a ser superado no final dos anos 1970, com a abertura da BR-101, a Rio-Santos, rede de integração que levou para o município de Paraty um incremento populacional ${ }^{8}$, particularmente urbano, e trouxe em seu eixo as novas formas e conteúdos da racionalidade moderna e do turismo (CAMARGO, 2013).

De volta ao patrimônio urbano, as ferramentas de proteção no âmbito federal também se multiplicam. A Secretaria de Planejamento da Presidência da República, com o apoio do Iphan, do Ministério do Interior e da Embratur cria, em 1973, o Programa Integrado de Reconstrução de Cidades Históricas (PCH), voltado, inicialmente, apenas para as cidades da região nordeste. Este programa investiu em infraestrutura urbana, em preservação do patrimônio arquitetônico, na orientação à elaboração de Planos Diretores e legislação urbana e, cabe destacar, associou o planejamento urbano e a preservação do patrimônio histórico ao uso turístico do território. Ao investir na implantação de circuitos turísticos e na capacitação técnica para formação de profissionais na área do restauro e da hotelaria, o governo federal aponta para o novo caminho das intervenções urbanas no planejamento territorial, apostando na refuncionalização turística dos centros históricos. Na mesma década, o programa é ampliado para o Rio de Janeiro, Minas Gerais e Espírito Santo, tendo sido extinto e relançado, em 1977, como Programa de Cidades Históricas. Em 1979, o programa é incorporado ao Iphan e ganha outras denominações.

O Programa de Revitalização de Sítios Históricos (PRSH), já de 1999, foi lançado pela Caixa Econômica Federal objetivando ações na área da reabilitação urbana e da preservação do patrimônio. De 2001 a 2006, por meio de um Acordo de Cooperação Técnica com o governo francês, este programa teve o mérito de unir investimentos em habitação (via créditos imobiliários) à preservação do patrimônio (BRASIL, 2008).

O Programa Urbis, de 2000, coordenado pelo Iphan, deixa o purismo da conservação de lado e traz uma concepção ainda mais clara do patrimônio cultural urbano como um elemento propulsor de desenvolvimento local. Para tanto, propõe a gestão compartilhada dos sítios históricos, e integra as fontes de investimentos financeiros da iniciativa privada e das diferentes políticas públicas, de modo a melhor gerir as aplicações dos recursos. Desse modo, propôs-se a orientar os municípios em suas ações e projetos destinados à preservação patrimonial e ao desenvolvimento urbano. Este programa foi implantado em vários municípios, entre eles Laguna (SC), Sobral (CE), Pirenópolis (GO), Mariana (MG), Cuiabá (MT), Manaus (AM) e Paraty (RJ). Neste mesmo período, em 2002, o Plano Diretor de Desenvolvimento Integrado do Município de Paraty é aprovado (PARATY, 2002).

O Programa Monumenta, iniciado em 2000 pelo Ministério da Cultura, teve o apoio da Unesco, financiamento do Banco Interamericano de Desenvolvimento (BID) e foi executado pelo Iphan como um dos maiores programas dentro desta concepção de conciliação entre a "recuperação e preservação do patrimônio cultural com desenvolvimento econômico e social" (BRASIL, 2008). Atuando em 26 cidades com sítios tombados pelo Iphan, as intervenções de restauração e recuperação de bens tombados esteve sempre associada às melhorias dos equipamentos urbanos, ao desenvolvimento local, à capacitação de mão de obra, aos programas educativos, enfim, à preservação e renovação dos sítios históricos (BONDUKI, 2010).

O papel sempre presente dos Programas Regionais de Desenvolvimento do Turismo (Prodetur), do Ministério do Turismo, ainda ativo em relação aos programas extintos já citados, comprova o diálogo entre a preservação do patrimônio cultural, o turismo e o planejamento urbano como o eixo de ações estruturadas e conjuntas das políticas públicas. No caso de Paraty, em 2003 foi realizado o Inventário Turístico (PARATY, 2003) e, em 2004, foi instituído o Plano Diretor de Desenvolvimento Turístico.

O programa em vigor mais importante e representativo desta nova concepção política, com verbas na casa dos 2 bilhões de reais, é o PAC Cidades Históricas (PAC-CH), que pretende "posicionar o patrimônio cultural como eixo indutor e

\footnotetext{
7 Em Paraty, existem seis unidades de proteção ambiental: Parque Nacional da Serra da Bocaina, Área de Proteção Ambiental do Cairuçu, Reserva Ecológica da Joatinga, Parque Ecológico de Paraty-Mirim, Área de Proteção Ambiental da Baía de Paraty e Estação Ecológica de Tamoios.

8 Segundo o Censo Demográfico do IBGE (2010), a população do município passou de 15.934, em 1970, para 20.626 em 1980. Em 2010, Paraty contava com 37.533 habitantes.
} 
Dossiê

estruturante" do desenvolvimento9. Paraty é uma das cidades selecionadas para receber recursos do PAC-CH. Atualmente, o Programa de Reabilitação Urbana do governo federal não se restringe às áreas centrais e segue esta concepção articulada entre políticas públicas e parcerias privadas.

As tentativas de inscrever Paraty como Patrimônio Mundial da Unesco se inserem nesta nova forma de reincorporação política e econômica das cidades a partir de seu capital cultural e ambiental. E Paraty, com a sua história colonial, com um conjunto arquitetônico de 460 imóveis na área tombada, e o entorno exuberante de Mata Atlântica, mar, ilhas, trilhas, rios e cachoeiras, sabe que possui atributos para concorrer.

Já nos anos 1980 ocorreu um primeiro movimento de conscientização de sua população sobre a importância de receber o título da Unesco e, em 2001, é realizado o Seminário Planejamento e Patrimônio Cultural-Paraty, quando é redigida a Carta de Paraty (IHAP, 2009) com o objetivo de lançar sua candidatura. Em 2003, a Prefeitura publica o Decreto Municipal ${ }^{\circ}$ 080/2003, que institui a Comissão Permanente Pró Sítio do Patrimônio Mundial de Paraty (PLANO DE GESTÃO, 2008).

Cabe lembrar que, desde os anos 1970, após a construção da BR-101, muitos migrantes, inclusive estrangeiros, chegam à cidade, o que faz alterar o seu perfil social e econômico. Além de trabalhadores para a construção civil e para os serviços terciários, com menor poder aquisitivo, há a formação de um grupo mais hegemônico no que concerne às decisões políticas, vindos, sobretudo, do Rio de Janeiro e de São Paulo, composto por profissionais liberais, empresários, artistas, intelectuais, cientistas, ambientalistas, entre outros, o qual seria decisivo para mobilizar uma mudança nas posturas políticas, sobretudo no que concerne à cultura, ao meio ambiente e às escolhas do município em relação ao turismo.

Sem a aprovação da Unesco em sua primeira inscrição, que priorizava a importância de Paraty no conjunto de cidades históricas brasileiras, a Prefeitura Municipal, juntamente ao Iphan, à Fundação Roberto Marinho e representantes da população, decidiram "mudar o foco do centro histórico da cidade para o Caminho do Ouro, pois o mesmo envolve patrimônio natural e cultural e, por isso, poderia lograr o título" (PADILHA, 2011, p. 42). A proposta mais abrangente, denominada O Caminho do Ouro em Paraty e sua paisagem, foi apresentada à Unesco em 2008, mas, mais uma vez, a candidatura não foi aprovada.

Desde então, a comissão permanente dos trabalhos de candidatura de Paraty tem atuado na elaboração de um terceiro dossiê para pleitear, desta vez, o reconhecimento de Paraty Patrimônio Mundial como sítio misto, isto é, como patrimônio cultural e natural, "enfatizando sua formação a partir do século XVIII e destacando como característica singular o traçado urbano, testemunha dos saberes tradicionais e onde as águas entram, obedecendo o ritmo das marés" (IHAP/ CARTA DE PARATY, 2011).

A proposta, apresentada na $33^{\circ}$ Sessão do Comitê do Patrimônio Mundial, sediada em Sevilha, em 2009, foi indicada para revisão para indicações futuras como sítio misto (IHAP, 2011), já que a cidade, segundo os critérios da Unesco, deve resolver problemas em relação ao saneamento urbano. Assim, após intervenções e investimentos públicos para sanear a cidade, o processo está sendo finalizado para ser reencaminhado. As áreas candidatas ao Patrimônio da Humanidade, no processo enviado para a candidatura, correspondem: à paisagem que circunda a cidade, integrada ao centro histórico, com o seu conjunto de edificações do século XVIII e XIX; ao Caminho do Ouro; e ao Forte do Defensor Perpétuo, área de propriedade do governo federal, não podendo ser edificada.

Nos últimos anos, vários projetos de melhorias urbanas e de conservação patrimonial vêm sendo efetuados no sítio histórico (centro e monumentos isolados), visando responder aos quesitos necessários para o seu reconhecimento como Patrimônio Mundial, e conciliar a conservação patrimonial com o desenvolvimento urbano e turístico ${ }^{10}$. Em 2007, buscando responder a um dos critérios da Unesco, a Prefeitura Municipal aterrou a rede de energia elétrica, retirou das ruas os postes e os cabos de energia e implantou uma iluminação feita por lampiões e luminárias características do século XVII. Tudo muito lindo, mas o esgoto ainda corria a céu aberto em pleno século XXI, e isso a Unesco não poderia aprovar. Então, tendo em vista o título, várias obras estão em curso, o que coloca o patrimônio fazendo às vezes das intervenções urbanas

9 O PAC-CH foi lançado em 2009 e é articulado pela Casa Civil da Presidência da República, em parceria com o Ministério da Cultura, por meio do Iphan e dos Ministérios do Turismo, da Educação e das Cidades, Petrobras, Eletrobrás, BNDES (Banco Nacional do Desenvolvimento Econômico e Social), Caixa Econômica Federal e Banco do Nordeste do Brasil. (DIÁRIO DO VALE, 2010).

10 Segundo o Plano de Gestão (2008, p. 94), até aquele momento, entre os projetos já implantados ou em fase de implantação, se destacavam: o Projeto de Iluminação Urbana do Centro Histórico (convênio entre Furnas - Centrais Elétricas Brasileiras, Eletrobrás, Companhia de Eletricidade (RJ), Secretaria de Estado de Energia da Indústria Naval e do Petróleo, Município de Paraty, Iphan e Fundação Roberto Marinho); o sistema de esgotamento sanitário; a Restauração da Casa da Cultura (Lei de Incentivo à Cultura, General Electric, Spring Carrier, Votorantim, Prefeitura Municipal de Paraty, Fundação Roberto Marinho e Rede Globo de Televisão); o Plano Diretor de Desenvolvimento Turístico (PDDT) do município de Paraty (PARATY, 2003), e a Restauração da Igreja Matriz de Paraty (Petrobrás). 
inexistentes. Entre elas, cabe destacar a obra de um adequado sistema de esgotamento sanitário ${ }^{11}$, que está sendo realizada e beneficiará cerca de 70\% de sua população; a construção de reservatórios; a complementação de abastecimento de água potável, enfim, os direitos básicos da urbanidade estão sendo estendidos para a sua população.

Nesse sentido, como na maioria dos casos de sítios históricos urbanos patrimonializados, concordamos com Lazzarotti (2011, p. 279) para quem a visibilidade dos lugares, tornada possível pela patrimonialização, é complementar ao turismo que põe em evidência as singularidades locais. Essa tríade - patrimônio, turismo e renovação urbana - faz parte do planejamento das cidades em tempos de economia global, e cada um dos seus termos não pode ser tomado separadamente, pois as luzes que focam o patrimônio cultural e atraem o turismo também colocam em evidência os problemas socioespaciais do lugar.

\section{Caminhos e descaminhos do turismo no patrimônio cultural de Paraty}

Paraty era a quinta cidade mais visitada do Brasil em 2008, com 280 mil visitantes por ano, sendo 15\% de estrangeiros, e a maior parte dos turistas provindo do Rio de Janeiro e de São Paulo. É o turismo a economia mais atrativa de Paraty e a principal fonte de renda de sua população (PLANO DE GESTÃO, 2008, p. 15).

Já em 1999, o Sebrae - Rio de Janeiro, com o apoio da Fundação Getúlio Vargas, implantou ali o Programa de Desenvolvimento Local Integrado e Sustentável (DLIS), o que promoveu maior participação da população local nas questões políticas do município. Segundo a imprensa local, o programa foi revisto em 2000 e, em 2009, foi obtida a aprovação da Lei no 1.722/2009, que instituiu o Fórum DLIS como o espaço de construção da Agenda 21 de Paraty (FOLHA, 2015). Embora a ampliação de instrumentos para uma democracia participativa seja um fato positivo, ela não inclui, necessariamente, todos os grupos sociais no debate sobre o território onde as questões do desenvolvimento local se colocam. É uma arena de conflitos de interesses crescentes, em um município que oferta a urbanidade de maneira desigual.

Segundo os documentos do patrimônio, na área do sítio histórico, não ocorre muita pressão construtiva devido à normatização da área tombada; contudo, em seu entorno, na área de amortecimento, "a expansão horizontal é intensa e vem reduzindo o Sítio Histórico a um apêndice insignificante de uma vizinhança extensamente edificada e em acelerado processo de decomposição urbana” (PLANO DE GESTÃO, 2008, p. 45), ainda que este problema tenha sido minimizado pelo tombamento do município e pelo Plano Diretor de Uso do Solo e Posturas, tendo em vista a conservação do patrimônio natural e edificado.

Desde os anos 1970, o turismo tornou-se um importante vetor das transformações socioespaciais da região, incluindo o litoral norte do Estado de São Paulo, que também sofreu os impactos da urbanizaçãa turística (LUCHIARI, 2000), potencializada pela construção da BR-101. Além das infraestruturas e serviços necessários para atendê-la, há uma mudança funcional e simbólica nos usos do sítio histórico, que deixa evidente os contrastes entre a qualidade de vida no turístico centro histórico e aquela ocorrida na Ilha das Cobras ou Mangueira, bairros precários onde vive a população local de baixa renda. A cidade partida é uma realidade difícil de contornar.

Além das residências estarem divididas entre permanentes e temporárias, no centro histórico ocorreu uma progressiva substituição dos moradores locais pelos de fora, e das habitações pelo comércio turístico, o que gera uma dinâmica esquizofrênica aos lugares, ou, na melhor das hipóteses, a substituição de um lugar por outro - aquele constituído de fora, a partir da implantação de territorialidades estrangeiras. Segundo o próprio Plano de Gestão (2008, p. 48), “observa-se uma linha divisória qualitativa muito clara entre o Sítio Histórico e o restante da área urbana", com o uso turístico excessivo incomodando a população local. Como vemos na Imagem 2, o Centro Histórico representa uma área muito pequena em relação ao município de Paraty.

Segundo depoimento de um morador local, quando perguntado sobre os pontos negativos da cidade de Paraty para se morar ${ }^{12}$, "a maior parte dos residentes do Centro Histórico são gringos e se acham per-

11 Usando uma tecnologia moderna de esgotamento sanitário a vácuo e lacrado, o sistema não será muito invasivo em seu calçamento tradicional. As pedras-pé-de-moleque são retiradas, numeradas e recolocadas no lugar. A obra está sendo executada por meio de Parceria Público Privada (PPP), com recursos municipais, estaduais, da Eletrobrás-Eletronuclear e da empresa vencedora para execução da obra, que durará quatro anos (PARATY, 2015a).

12 Algumas entrevistas com moradores de Paraty, incluídas neste artigo, resultam de Trabalho de Campo realizado com alunos da disciplina GF 402 - Meio Ambiente Urbano, sob minha responsabilidade, do curso de graduação em Geografia da Universidade Estadual de Campinas (Unicamp), em junho de 2014. Foram aplicados 108 questionários, cada um com 06 (seis) questões abertas, todos no centro histórico de Paraty, exclusivamente com habitantes do município, moradores ou usuários do centro histórico. 
tencentes ao lugar”. Estes gringos são franceses, argentinos, alemães, entre outros, que fixaram residência no centro histórico de Paraty e estão presentes também em seus ateliês, restaurantes e no comércio turístico. Isso não seria um problema não fosse o fato da vertiginosa valorização imobiliária destes imóveis que, direta ou indiretamente, expulsou a antiga população de moradores. Para a grande maioria dos moradores locais, o centro é apenas o lugar do trabalho e do lazer nos finais de semana ou festividades. Embora o centro seja dividido entre moradia, comércio ou edificações mistas, este não é um comércio acessível à maior parte da população devido aos altos preços que as mercadorias agregaram com a chegada do turismo.

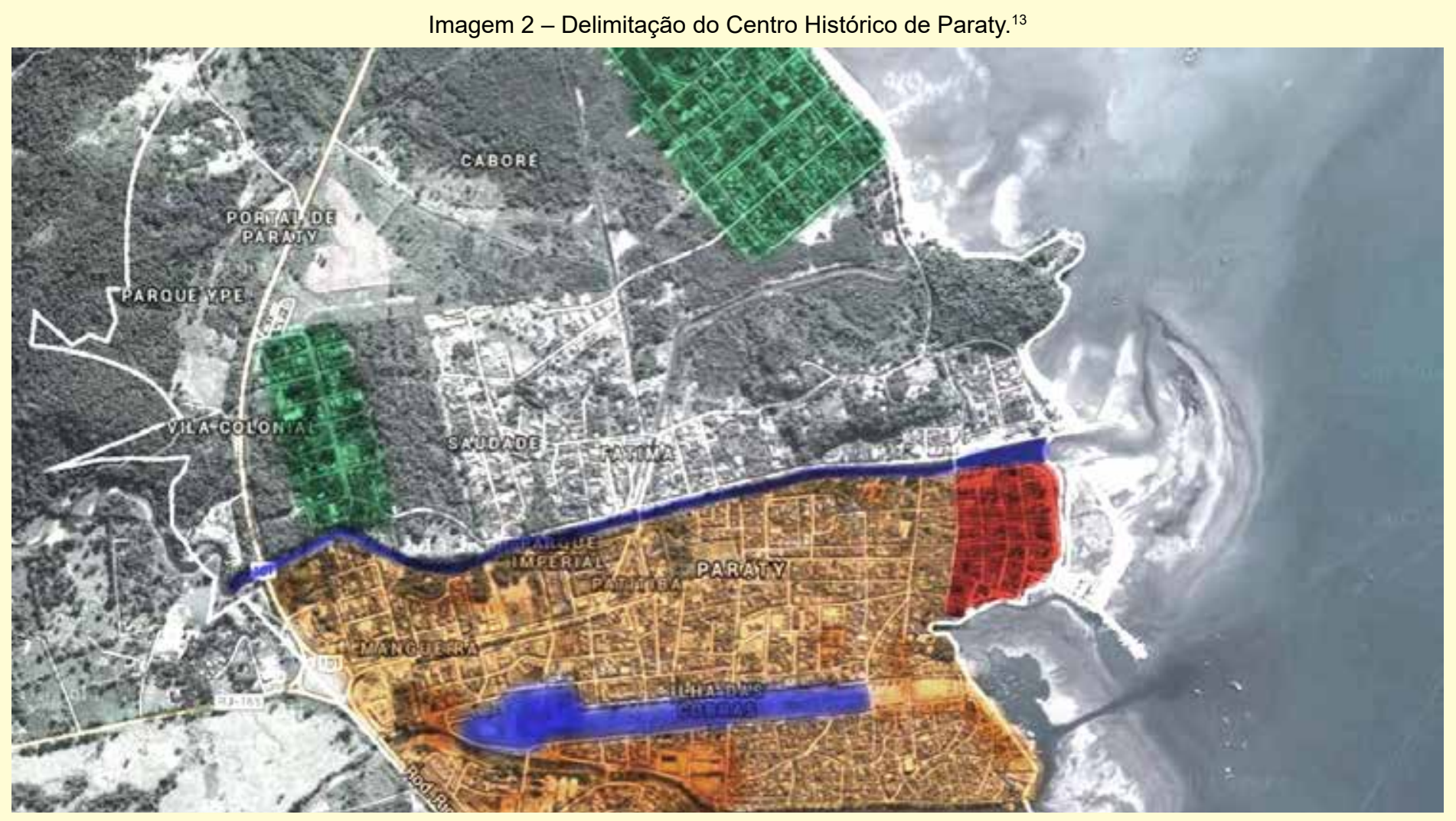

Fonte: SOARES (2013).

Quando perguntados sobre os aspectos positivos de se morar em Paraty, as respostas dos moradores concentram-se na beleza do centro histórico, nas festas e nas atividades do turismo, fala contraditória que merece atenção em relação aos aspectos negativos por eles citados: problemas relacionados ao turismo, tais como a falta de segurança, o aumento da criminalidade, o lixo deixado na cidade após as festas, o aumento do consumo de drogas, o alto custo dos passeios ecológicos e marítimos, entre outros. O turismo é bom para a localidade, mas é necessário que os seus moradores continuem sendo os sujeitos do lugar.

Além disso, a substituição das práticas da cultura local por uma agenda cultural - característica marcante na turistificação dos lugares - separa a riqueza dos eventos culturais das mazelas cotidianas vividas pela população local. Algumas tradições religiosas ou populares são reinventadas ou fortalecidas, como a Folia de Reis, as cirandas com equipamentos eletrônicos, o carnaval, a Festa do Divino, as Festas de São João, São Pedro, São Paulo, São Benedito, Santa Rita, N.S. do Rosário, a procissão de Corpus Christi, entre outras; ou criadas especialmente para o turismo, caso do Dia do Caminho do Ouro, dos festivais musicais (Bourbon; Mimo), de artes (Paraty em Foco), cinema, literatura (Flip) e cultura (Paraty Eco Fashion), do Festival do Camarão, da Cachaça, dos Encontros de Ceramistas, de Mitos e Lendas Indígenas, da Cultura Negra, do Paraty Spa Days.

Entre estas, a Festa Literária Internacional (Flip), criada em 2003, é, sem dúvida, o evento mais mobilizador de mudanças em Paraty, a partir de uma agenda sociocultural e do centro histórico tomado como cenário da festa. Tais mudanças referem-se tanto à imagem de Paraty que é divulgada fora, quanto à Paraty real que deve adequar-se para receber seus importantes visitantes. Em sua $13^{\circ}$ edição, em 2015, a festa recebeu cerca de 30.000 visitantes

$13 \mathrm{Na}$ imagem, em vermelho localiza-se o centro histórico, em verde temos loteamentos mais planejados, em azul vemos elementos de divisão, como era o porto e o rio, e, em laranja, áreas de crescimento sem planejamento da cidade (Ilha das Cobras). 
durante a semana, com quase $100 \%$ de taxa de ocupação em seu receptivo hoteleiro ${ }^{14}$ e restaurantes. Segundo o jornal eletrônico El País,

\begin{abstract}
Sebastian Boffa, da Paraty Convention Bureau, uma associação privada do setor de turismo, afirma que chegam mais e mais turistas - brasileiros e estrangeiros - a cada ano. 'É comum ter a ocupação dos leitos próxima a 100\%”, diz o empresário argentino que está à frente da primeira operadora turística da cidade, a Paraty Tours, há 24 anos. 'Recebemos visitas de todas as partes. Paraty está hoje nas prateleiras de agências de turismo do mundo todo (MORAES, 2015).
\end{abstract}

Em sua 9a edição, em 2011, segundo a Embratur, “o patrocínio do BNDES colaborou para a revitalização e valorização do patrimônio arquitetônico e imaterial de Paraty” (PORTAL BRASIL, 2015). A Casa da Cultura, no centro histórico, foi projetada para servir à Flip mas, segundo os secretários de planejamento e de turismo de Paraty ${ }^{15}$, é também um equipamento cultural que serve à população de moradores. Também associada à Flip foram construídas bibliotecas comunitárias e em escolas, organizados cursos de formação em literatura para professores e alunos, doados livros e realizadas oficinas de preparação de crianças e adultos para que estes também participem da festa.

Claro que todo este movimento cultural anima a cidade e traz novas possibilidades para a população local, tanto culturais quanto econômicas. Contudo, aquela cidade partida citada antes, também ganha luz durante a festa. Com cartazes em que se lia "paratiense também é gente”, um grupo organizado de moradores protestou diante das portas das tendas dos autores convidados em 2015, questionando a grande cobertura policial apenas durante o evento. Segundo a imprensa, o aumento da criminalidade em Paraty é latente:

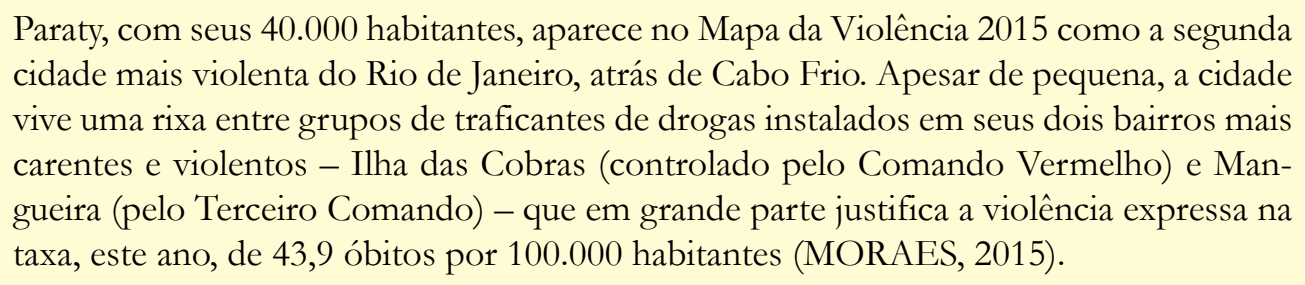

Depois de 2008, o espraiamento dos grupos organizados do narcotráfico, após a implantação das Unidades de Polícia Pacificadora (UPPs) na cidade do Rio de Janeiro, atingiu inúmeros municípios fluminenses. E não há como separar estas questões em um país de desenvolvimento desigual. A cidadania, para ser exercida nestas condições, carece de poder aquisitivo, e aí, já não estamos falando do cidadão, mas do consumidor. $\mathrm{O}$ acesso à segurança ou ao consumo cultural não é democraticamente distribuído, são mercadorias acessíveis somente aos usuários solventes (BORJA \& CASTELLS, 1997), público este que será sempre bem resguardado e protegido nos lucrativos eventos culturais. Por isso a revolta da população diante de um evento tão glamouroso quanto fantasioso em relação à realidade local na qual a maior parte dos moradores vive. Como afirma Choay (2001, p. 224), a "indústria do patrimônio cultural desenvolveu recursos de embalagem que também permitem oferecer os centros e os bairros antigos como produtos do consumo cultural”. E, se “a ideia é não esquecer”, como afirmam Schwarcz e Starling (2015, p. 500), essa

enraizada e longa experiência social da escravidão [...] continua presente ainda nos dias de hoje, na nossa arquitetura (nos minúsculos "quartos de empregada" ou nos elevadores de serviço - na verdade para serviçais), no nosso vocabulário, nas práticas cotidianas de discriminação social e racial ou de culpabilização dos mais pobres, com frequência negros.

Mas a questão estrutural da desigualdade social vivida no Brasil não cabe ao patrimônio ou ao turismo resolver isoladamente, embora ambos, junto às políticas de planejamento territorial e às intervenções priva-

14 A Secretaria Municipal de Turismo de Paraty apresenta os resultados de uma pesquisa realizada sobre os meios de hospedagem e as taxas de ocupação durante todo o ano de 2013. Em uma amostragem de 47 hotéis obteve: Econômico (25; 90\%), Confortável (16, 88\%) e Luxo (06; 100\%) (PARATY, 2015b).

15 Durante o Trabalho de Campo já citado, foi realizada uma reunião na Casa da Cultura de Paraty, no dia 30.05.2014, com os secretários de Planejamento, Turismo, Meio Ambiente e Urbanismo. Parte das informações citadas aqui devem-se às suas falas. 
das, introduzam novas formas de convivência que podem fortalecer ou enfraquecer tal estrutura de desigualdade.

Ainda que uma grande parte de moradores entrevistados também teça críticas ao planejamento urbano e à falta de acesso ou ausência de vários indicadores de qualidade de vida (rede de esgotos, aumento do lixo nas temporadas, especulação imobiliária, aumento do custo de vida, entre outros), a maioria defende a expansão de um turismo melhor planejado e controlado como estratégia de desenvolvimento local, já que, segundo um dos entrevistados, "sem o turismo Paraty não sobrevive".

Mesmo em relação à morfologia do tecido urbano, embora o planejamento da cidade tenha tido especial cuidado com a criação de um zoneamento e de restrições do uso do solo, em particular para o Bairro Histórico, que mantém a proibição da entrada de automóveis para a proteção do calçamento e das edificações, a fiscalização das obras é um problema recorrente em nossas cidades e várias obras novas, reformas, reparos, demolições, assim como a pressão do excessivo uso turístico, descaracterizam o conjunto original tombado. A proibição de novas edificações no centro histórico é antiga, com a preservação do gabarito do conjunto que mantém o núcleo de, no máximo, três pavimentos, mas algumas edificações em estilo patrimônio foram autorizadas a partir de meados do século XX, falseando, muitas vezes, o valor histórico do conjunto. O preenchimento de lotes vazios, estratégia presente na Carta de Veneza e na história de Paraty, ainda que seja constituído de muros, construções modernas ou pós-modernas, proporciona uma percepção de contiguidade e articulação da morfologia do sítio antigo, mesmo que as construções não sejam originais. Como afirma Choay (2001, p. 225), os novos elementos arquitetônicos "servem à imagem midiática da cidade".

Ainda que se considere o turismo um dos principais vetores na transformação dessas cidades históricas brasileiras, cabe lembrar que, ao longo do tempo, o que vemos como conjunto paisagístico harmonioso já foi objeto de várias intervenções formais e funcionais. Paraty, ao longo do século XIX, recebeu diversas influências diferentes das referências coloniais, e substituiu vários elementos construtivos: "as rótulas, muxarabis e portadas cegas de madeira, por janelas envidraçadas com caixilhos, e os guarda-copos das sacadas em treliça de madeira, cederam lugar ao gradeamento em ferro forjado, com motivos ornamentais geométricos” (PLANO DE GESTÃO, 2008, p. 121).

Enquanto a imagem do sítio histórico colonial, do ouro e suas trilhas, é divulgada turisticamente como principal referência imagética, o conjunto arquitetônico é, em grande parte, dos séculos XIX e XX, e não do século XVIII. Na verdade, pouco sabemos do século XX, período histórico esquecido pelos inventários do tombamento, mas, como afirma o Plano de Gestão (2008, p. 123):

\footnotetext{
Nas décadas de 60 e 70 foram utilizados de forma exagerada elementos decorativos, sobrepostos principalmente a frisos, faixas e fustes de cunhais de prédios assobradados, e mesmo em algumas casas térreas, acentuando formas bizarras pela utilização de cores primárias, frequentemente com objetivos falsamente cenográficos.
}

Então, ainda que na forma de uma análise sucinta, como a desenvolvida neste artigo, fica claro o papel da cenarização para a valorização econômica atual destes sítios históricos. E aqui não teço nenhum julgamento de valor, apenas indico que devemos estar mais atentos às disputas de interesses em relação ao valor cultural e turístico dos lugares, assim como deixarmos para trás as análises mais puristas sobre a preservação patrimonial.

Se no início do século XX a patrimonialização serviu para reforçar a identidade nacional nas ideologias políticas do Estado-Nação, no final do século XX e início do XXI a turistificação do patrimônio cultural vem reforçar as políticas em sua rede de conexões com a economia global, que se apoderou da cultura como recurso econômico, como ideologia política e como normatização do território.

Como foi permeado durante todo este artigo, o processo de patrimonialização dos sítios históricos brasileiros, particularmente o de Paraty, não respondeu somente às questões culturais, mas às políticas públicas de renovação urbana que, associadas ao planejamento turístico, buscaram fortalecer a economia política das cidades. Hoje, se o turismo se sobrepõe ao desenvolvimento local, esta balança se desequilibra, da mesma forma que ocorre quando o patrimônio cultural é pensado como instância separada - basta constatar as exigências de desenvolvimento urbano da Unesco em relação à cidade de Paraty para que esta seja aprovada como Patrimônio Mundial. A mensagem é direta: sem desenvolvimento local, não há patrimônio mundial. Sem a renovação da infraestrutura urbana, não há o título da Unesco.

Desse modo, é muito importante analisar não apenas as oposições entre preservar o patrimônio e renovar 
o espaço urbano, mas, exatamente, os alinhamentos e os modos de estruturação dos consensos entre os atores aparentemente em oposição. Além disso, as relações entre turismo, patrimônio cultural e planejamento territorial, expõem uma nova forma de participação social dos grupos localmente envolvidos, visões plurais e divergentes.

Por isso, a matriz de interpretação de tal processo não pode reduzir-se a um setor, olhar ou ciência, devendo enfrentar o cruzamento complexo entre patrimônio cultural, turismo e planejamento territorial.

\section{Referências}

BONDUKI, Nabil. Intervenções urbanas na recuperação de Centros Históricos. Brasília: Programa Monumenta/Iphan, 2010.375 p. BORJA, J.; CASTELLS, M. Localy global. La gestión de las ciudades en la era de la información. United Nations for Human Settlements (Habitat). Madrid: Taurus/Pensamiento, 1997.

BRASIL. Decreto no 58.077, de 24 de março de 1966. Converte em monumento nacional o município fluminense de Paraty

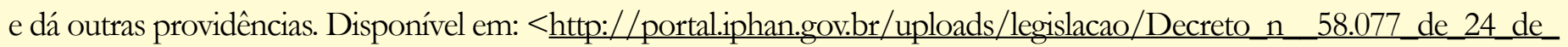
marco de 1966.pdf>. Acesso em: set. 2015.

. Ministério das Cidades. Manual de Reabilitação de Areas Urbanas Centrais. Brasilia: Ministério das Cidades, 2008.

. Ministério das Cidades. Política de reabilitação de áreas urbanas centrais. In: Cadernos MCidades/Programas Urbanos

- Planejamento territorial urbano e política fundiária - 3. Brasilia: Ministério das Cidades, 2004. p. 69-84.

. Ministério das Cidades. Reabilitação de centros urbanos. Brasilia: Ministério das Cidades, 2005. 84 p. n. 3.

CAMARGO, C.P.M.P. Territorialidades caiçaras do tempo de antigamente ao tempo de hoje em dia em Paraty, RJ - Vila Oratório, Praia do Sono, Ponta Negra e Martin de Sá. 2013. Dissertação (Mestrado em Geografia) - Universidade Estadual de Campinas, Campinas. 2013.

CARTA DE VENEZA. 1964. Disponível em: $<$ http://portal.iphan.gov.br/uploads/ckfinder/arquivos/Normas $\% 20 \mathrm{de} \% 20$ Quito\%201967.pdf>. Acesso em: set. 2015.

CHUVA, Márcia R.R. Os arquitetos da memória - sociogênese das práticas de preservação do patrimônio cultural no Brasil (anos 1930-1940). Rio de Janeiro: Editora UFRJ, 2009.

COSTA, Nilson do Rosário. A questão sanitária e a cidade. NERU - Espaço e Debates, São Paulo, v. 7, n. 22, p. 5-25, 1987.

CURY, Isabelle. Paraty. In: PESSÔA, J.; PICCINATO, G. Atlas dos centros históricos do Brasil. Rio de Janeiro: Casa da Palavra, 2002. p. 178-185.

DIÁRIO DO VALE. Seis cidades da região vão receber recursos do PAC das Cidades Históricas. Volta redonda, 19 mar. 2010. Disponível em: $<$ http://www.diariodovale.com.br/noticias/0,18553,Seis-cidades-da-regiao-vao-receber-recursos-do-PAC-das-Cidades-Historicas.html\#ixzz3mslfEsfN>. Acesso em: set. 2015.

FOLHA DO LITORAL COSTA VERDE. DLIS Agenda 21. Disponível em: < $\underline{\text { http://folhadolitoralcostaverde.com/ }}$ wordpress/?page $\mathrm{id}=250>$. Acesso em: set. 2015.

GURGEL, H.; AMARAL, E. Paraty, Caminho do Ouro. Rio de Janeiro: Editora Bertrand, 1973.

IBGE. 2010. Cidades. Rio de Janeiro. Paraty. Censo Demográfico 2010. Disponível em: < http://www.cidades.ibge.gov.br/xtras/ perfil.php?lang $=\&$ codmun $=330380 \&$ search=rio-de-janeiro $\mid$ paraty $>$. Acesso em: 30 jul. 2015.

INSTITUTO HISTÓRICO E ARTÍSTICO DE PARATY (IHAP). Carta de Paraty, Rio de Janeiro, 2011.

IPHAN. Processo de Tombamento n 563, T-57. Inscrição: Conjunto Arquitetônico e Paisagístico do Município de Paraty, Estado do Rio de Janeiro, 1958.

KUHL, Beatriz Mugayar. Conservação e restauração - Notas sobre a Carta de Veneza. Anais do Musen Paulista: História e Cultura Material, São Paulo, v. 18, n. 2, 2010.

LAZZAROTTI, Olivier. Patrimoine et tourisme: Histoires, lieux, acteurs, enjeux. Paris: Éditions Belin, 2011. 302 p. (Tourisme). 
Dossiê

LEAL, C.F.B. (Org.). As missões da UNESCO no Brasil: Michel Parent. Rio de Janeiro: Editora, 2008. 343 p. (Série: Pesquisa e Documentação do IPHAN).

LUCHIARI, M. T. D. P. A reinvenção do patrimônio arquitetônico no consumo das cidades.GEOUSP - Espaço e Tempo, São Paulo, n. 17, p. 95-105, 2005.

. Urbanização Turística: um novo nexo entre o lugar e o mundo. In: SERRANO, C.M.T.; BRUHNS, H.T.; LUCHIARI, M.T.D.P. (Orgs.). Olhares contemporâneos sobre o turismo. Campinas: Papirus, 2000. p. 105-130. (Coleção Turismo).

MORAES, Camila. Quando as luzes se apagam em Paraty. El País, Paraty, 5 jul. 2015. Disponível em: < $\underline{\text { http://brasil.elpais. }}$ com/brasil/2015/07/04/politica/1436039196 544016.html>. Acesso: set. 2015.

ORGANIZAÇÃO DOS ESTADOS AMERICANOS (OEA). Normas de Quito. 1967. Reunião sobre conservação e utilização de monumentos e lugares de interesse histórico e artístico. Disponível em: < $\underline{\text { http://portal.iphan.gov.br/uploads/ckfin- }}$ der/arquivos/Normas\%20de\%20Quito\%201967.pdf>. Acesso em: 30 jul. 2015.

PADILHA, M. do N. Espaço público e patrimônio histórico em Paraty, RJ: entre o espaço do cidadão e o espaço do turista. 2011. Tese (Doutorado em Geografia) - Universidade Federal Fluminense, Niterói. 2011.

PAES, M.T.D. Refuncionalização turística de sítios urbanos históricos no Brasil: das heranças simbólicas à reprodução de signos culturais. Revista Geografia, Rio Claro, v. 37, n. 2, p. 319-334, 2012.

PARATY. Câmara Municipal. Lei Complementar no 020/2004. Institui o Plano Diretor de Desenvolvimento Turístico do Município de Paraty. Disponível em: <http://www.paraty.ri.gov.br/camaraparaty/painel/Leis/2004/Lei Complemen-

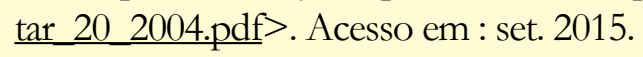

2002. Prefeitura Municipal. Lei no 1352, de 2002. Institui o Plano Diretor de Desenvolvimento Integrado do Município de Paraty. Disponível em: < http://www.paraty.ri.gov.br/camaraparaty/painel/Leis/2002/Lei 1352 2002.pdf> . Acesso em: set. 2015.

. Prefeitura Municipal. Pesquisa Hoteleira. Disponível: $<\underline{\text { http://pmparaty.ri.gov.br/conteudo/acoeseprojetos/ }}$ Pesquisa-Hoteleira.pdf>. Acesso em: set. 2015b.

. Prefeitura Municipal. Saneamento. Disponível em: $<\underline{\text { http://pmparaty.ri.gov.br/page/servicosdetalhes. }}$ aspx?tipo $=$ saneamento-basico $>$. Acesso em: set. 2015a.

. Prefeitura Municipal. Secretaria de Turismo e Cultura. Solving Consultoria em Turismo. Ibama. IEF (RJ). Sebrae (RJ). S.O.S. Mata Atlântica. TurisRio. Plano de desenvolvimento turístico do Município de Paraty - Inventário Turístico. Rio de Janeiro: Companhia de Turismo do Estado do Rio de Janeiro, 2003.

PEET, Richard. A produção cultural de formas econômicas. Experimental, São Paulo, ano 2, n. 3, p.117-136, 1997.

PLANO DE GESTÃO. Paraty Patrimônio da Humanidade - Versão Preliminar. Grupo de Trabalho da Comissão Permanente Pró Sítio do Patrimônio Mundial de Paraty, RJ, 2008.

PORTAL BRASIL. BNDES patrocina $9{ }^{\circ}$ edição da Festa Literária Internacional de Paraty (RJ). Disponível em: < http://www.brasil. gov.br/cultura/2011/07/bndes-patrocina-9b0-edicao-da-festa-literaria-internacional-de-paraty-ri> . Acesso em: set. 2015.

RIBAS, Marcos C. A história do Caminho do Ouro em Paraty. Rio de Janeiro: Grupo Contadores de Histórias/Contest Produções Culturais, 2003.

SANT'ANNA, M. A. Recuperação do Centro Histórico de Salvador: Origens, Sentidos e Resultados. Rua - Revista de Arquitetura e Urbanismo, Salvador, n. 8, p. 8-59, 2003.

SCHWARCZ, L. M.; STARLING, H. M. Brasil: uma biografia. São Paulo: Companhia das Letras, 2015.

SOARES, Beatriz Tsung Lima. Relatório de campo para Disciplina GF 702 - Meio Ambiente Urbano. Bacharelado em Geografia, Instituto de Geociências, Universidade de Campinas, 2013.

TEMPORADA LIVRE. Saiba mais sobre a vida cultural de Paraty, Rio de Janeiro, 5 ago. 2015. Disponível em: < http://www.temporadalivre.com/blog/saiba-mais-sobre-vida-cultural-de-paraty-rio-de-janeiro >. Acesso em: set. 2015.

YÚDICE, George. A conveniência da cultura - usos da cultura na era global. Belo Horizonte: Editora UFMG, 2013. (Coleção Humanitas). 